\title{
Autosomal dominant secondary polycythemia
}

INSERM

\section{Source}

INSERM. (1999). Orphanet: an online rare disease and orphan drug data base. Autosomal dominant secondary polycythemia. ORPHA:247511

Autosomal dominant secondary polycythemia is a rare, genetic, hematologic disease characterized by increased levels of serum hemoglobin, hematocrit and erythrocyte mass, associated with elevated or inappropriately normal erythropoietin serum levels, occurring in various members of a family and with autosomal dominant inheritance. 